\title{
Prevalence and predictors of depression among emergency physicians: a national cross- sectional study
}

Yueming Chen ${ }^{1 \dagger}$, Xin Shen ${ }^{2 \dagger}$, Jing Feng ${ }^{2}$, Zihui Lei ${ }^{2}$, Weixin Zhang ${ }^{3}$, Xingyue Song ${ }^{4^{*}}$ and Chuanzhu LV ${ }^{5,6^{*}}$

\begin{abstract}
Background: Physicians' depression can damage their physical and mental health and can also lead to prescribing errors and reduced quality of health care. Emergency physicians are a potentially high-risk community, but there have been no large-sample studies on the prevalence and predictors of depression among this population.

Methods: A nationally representative cross-sectional survey of 15,243 emergency physicians was conducted in 31 provinces across China between July and September 2019. Multivariable logistic regression analysis was performed to identify predictors of depression.

Results: A total of $35.59 \%$ of emergency physicians suffered from depression. Emergency physicians who were male $(\mathrm{OR}=0.91)$ and older $[>37$ and $\leq 43(\mathrm{OR}=0.83)$ or $>43(\mathrm{OR}=0.71)]$, had high $(\mathrm{OR}=0.63)$ or middle $(\mathrm{OR}=0.70)$ level income, and participated in physical inactivity $(\mathrm{OR}=0.85)$ were not more likely to suffer depression. Meanwhile, those who were unmarried $(\mathrm{OR}=1.13)$ and smokers $(\mathrm{OR}=1.12)$ had higher education levels [Bachelor's degree $(\mathrm{OR}=1.57)$ or Master's degree or higher $(\mathrm{OR}=1.82)]$, long work tenure $[>6$ and $\leq 11(\mathrm{OR}=1.15)$ or $>11 ; 11(\mathrm{OR}=1.19)]$, poorer health status [fair $(\mathrm{OR}=1.67)$ or poor $(\mathrm{OR}=3.79)$ ] and sleep quality [fair $(\mathrm{OR}=2.23)$ or poor $(\mathrm{OR}=4.94)]$, a history of hypertension $(\mathrm{OR}=1.13)$ and coronary heart disease $(\mathrm{OR}=1.57)$ and experienced shift work $(\mathrm{OR}=1.91)$ and violence $(\mathrm{OR}=4.94)]$.

Conclusion: Nearly one third of emergency physicians in China suffered from depression. Targeted measures should be taken to reduce the prevalence of depression to avoid a decline in health care quality and adversely impact the supply of emergency medical services.
\end{abstract}

\section{Background}

Depression is a chronic disease characterized by longterm low mood and lack of energy [1], which can harm mental and physical health $[2,3]$ and also contribute to a

*Correspondence: songxingyue2015@163.com; Ivchuanzhu677@126.com †Yueming Chen and Xin Shen contributed equally to this work.

${ }^{4}$ Department of Emergency, Hainan Clinical Research Center for Acute and Critical Diseases, The Second Affiliated Hospital of Hainan Medical University, No. 368 Yehai Avenue, Longhua Zone, Haikou 571199, Hainan, China

${ }^{5}$ Emergency Medicine Center, Sichuan Provincial People's Hospital, University of Electronic Science and Technology of China, No. 32 Yi Huan Lu Xi Er Duan, Chengdu 610072, Sichuan Province, China

Full list of author information is available at the end of the article burden of disease [4]. Approximately 350 million people worldwide suffer from depression [5], while health care workers are the most likely to have a high rate of this disease [6]. Previous studies have shown that the prevalence rate of depression among physicians is as high as $28.8 \%$, and $8 \%$ have admitted to suicidal ideation [7]. Physicians' depression can lead to chronic diseases $[8,9]$ and serious psychological problems [10] and can also adversely affect the quality of health care [11], such as increasing the incidence of medical errors and prescribing errors [12, 13].

Some potential predictors have been identified to contribute to depression among physicians, including excessive work stress and long working hours [14]. However, according to previous research, far more than general

(c) The Author(s) 2022. Open Access This article is licensed under a Creative Commons Attribution 4.0 International License, which permits use, sharing, adaptation, distribution and reproduction in any medium or format, as long as you give appropriate credit to the original author(s) and the source, provide a link to the Creative Commons licence, and indicate if changes were made. The images or other third party material in this article are included in the article's Creative Commons licence, unless indicated otherwise in a credit line to the material. If material is not included in the article's Creative Commons licence and your intended use is not permitted by statutory regulation or exceeds the permitted use, you will need to obtain permission directly from the copyright holder. To view a copy of this licence, visit http://creativecommons.org/licenses/by/4.0/. The Creative Commons Public Domain Dedication waiver (http://creativeco mmons.org/publicdomain/zero/1.0/) applies to the data made available in this article, unless otherwise stated in a credit line to the data. 
physicians (38\%), emergency physicians tend to experience higher levels of working stress (more than 60\%) $[15,16]$. Emergency physicians often need to deal with numerous patients and various diseases while providing medical services, and they also face staffing shortages and a chaotic work environment characterized by unpredictability in the medical setting [17]. Chronic work and psychological stress have become hidden dangers to the occurrence of depression among emergency physicians.

Although the consensus is that physicians are more likely to suffer from depression than the general public [18-21], most previous studies have focused on depression among surgeons [22], primary health care workers [23], and medical students [24], with few studies focusing on emergency physicians. In reality, a growing number of studies have pointed out that the prevalence of depression varies significantly between specialties $[21,25,26]$ and that targeted studies are needed according to the physician community. Previous studies have analysed the prevalence of depression among emergency physicians in the United Kingdom $(\mathrm{N}=371)$ [27], the United States $(N=763)$ [28], and Turkey $(\mathrm{N}=192)$ [29], but there is still a lack of representative large-sample studies. Therefore, the purpose of this study was to explore the prevalence and influencing factors of depression among emergency physicians based on a large nationwide sample. The results of this study could provide global health care policy-makers and researchers with more accurate reports on the prevalence of depression, which can be a reference for targeted measures to safeguard the psychological health of emergency physicians and ensure the quality of emergency medical services.

\section{Methods}

\section{Ethics statement}

The study protocol was approved by the Institutional Ethics Board of the Second Affiliated Hospital of Hainan Medical University, Haikou, China. All individuals provided written informed consent.

\section{Study participants and survey design}

Our study follows Strengthening The Reporting of OBservational Studies in Epidemiology

(STROBE) [30]. A cross-sectional study was carried out in China from July 2019 to September 2019. A multistage stratified random sampling design was used in this study. First, 31 Chinese provinces were classified as developed, developing, or less-developed regions according to per capital household income in 2018. Second, we randomly selected 10 hospitals from each province. Third, based on the number and scale of the hospitals, $40 \%$ of the emergency physicians who had practised in the emergency department for at least 6 months were randomly selected from each hospital to complete a self-administered questionnaire. The participants included only emergency physicians and not nurses or other technicians who provided emergency care. In our study, a 95\% confidence level and $\pm 5 \%$ precision were assumed for the following equation:

$$
\mathrm{n}=\frac{N}{1+N(e)^{2}}
$$

where $\mathrm{n}$ is the sample size, $\mathrm{N}$ is the population size, and $\mathrm{e}$ is the level of precision. Thus, the conservative total sample size for this questionnaire was 1400 .

\section{Instrument and measurement}

The questionnaire was designed based on literature reviews, group discussions, and preliminary interviews. Furthermore, a pilot study was conducted in one Wuhan community to improve the quality of the questionnaire. This questionnaire focuses on the physical and mental health and professional attitude of emergency physicians, and the relevant parts of this study include sociodemographic information (e.g., region, age, gender, education level, marital status, and professional title), workplace violence and depression.

\section{The Chinese version of the Workplace Violence Scale (WVS)}

The WVS was developed by Wang et al. [31] and has good reliability and validity for measuring the incidence of workplace violence when applied to medical staff in China. It includes 5 items measured with a four-point ordinal scale ranging from 0 (never) to 3 (more than 3 times/year). In this study, the Cronbach's alpha for WPV was 0.81 .

\section{The Center for Epidemiological Studies Depression scale (CES-D)}

The CES-D was used to assess depressive symptoms. The scale includes 20 items; each item is scored on a fourpoint scale ranging from 0 ("little or none of the time") to 3 ("most or almost all of the time"). The total score ranges from 0 to 60 points, and the higher the score, the more severe the depressive symptoms. On the original CES-D scale, a total score of 16 was used to detect the presence of depressive symptoms [32]. However, many studies have assessed the diagnostic accuracy of CES-D in detecting depression in the general population and have proposed multiple cut-off points, such as a cut-off point of 18 for elderly people living in residential homes [33] and a cut-off score of 22 for older Chinese individuals [34]. A meta-analysis systematically reviewed 28 CES-D studies, including several Chinese studies, and obtained an optimal cut-off of 20 points [35]. As a result, an overall score of 20 or higher was considered an indicator of 
depressive symptoms in this study, consistent with previous research [36]. The CES-D has good reliability and validity, and it has been widely used in the Chinese population. In this study, the Cronbach's alpha coefficient of the scale was 0.90 .

\section{Data collection and quality control}

A web link to the online questionnaire, which was designed using Questionnaire Star, was disseminated to the participants through WeChat (similar to WhatsApp in Western countries, WeChat is the largest communication platform in China, with over one billion users). To prevent the same participants from repeatedly answering the questionnaire, each device (e.g., smartphone or computer) was eligible to complete the questionnaire only once, and logical checks were concurrently run on the WeChat platform to identify invalid questionnaires. The data were entered into a web-based database by trained investigators to ensure accuracy.

\section{Statistical methods}

Descriptive analyses used means for the continuous variables and percentages for the categorical data. The descriptive statistics for the categorical variables were reported as the frequency (percentage) and were compared between having depression (CES-D Scores $\geq 20$ ) or not using Pearson's $X^{2}$ test. Depression was treated as the dependent variable and was a categorical variable. Multivariable logistic analysis (cut-offs for selection and elimination: $P=0.05$ and $P=0.10$, respectively) was used to calculate the odds ratios (ORs) and 95\% confidence intervals (CIs) for predictors that might be associated with the prevalence of depression. All analyses were performed using STATA 13.0, and all tests were two sided with a significance level of 0.05 .

\section{Results}

In total, 15,455 emergency physicians were asked to participate in this survey, and 182 physicians did not respond. Additionally, 30 questionnaires were discarded due to missing information. Ultimately, 15,243 eligible questionnaires were used in this analysis. Table 1 presents the main characteristics of the survey respondents. Among the 15,243 respondents, most were married (83.26\%), were men (69.87\%) and had a Bachelor's degree or above (94.18\%). The mean age (SD) was $37.66(8.06)$ years. Approximately $65 \%$ of the participants had intermediate or senior professional titles. In total, $55.23 \%$ of the respondents were in the middle-income and lowerincome groups, more than half estimated their own health to be at the general level, and approximately $40 \%$ were from developing regions. A minority of the participants $(27.19 \%)$ participated in regular physical activity.
Table 1 Statistical description of study samples

\begin{tabular}{|c|c|c|c|c|}
\hline Variables & N (\%) & $\begin{array}{l}\text { Depression } \\
\text { (CES-D Scores } \\
\geq 20 \text { ) }\end{array}$ & $x^{2}$ & $P$ value \\
\hline Total & $15243(100.00)$ & $5425(35.59)$ & NA & NA \\
\hline \multicolumn{5}{|l|}{ Gender } \\
\hline Male & $10650(69.87)$ & 3854 (36.19) & 5.50 & 0.02 \\
\hline Female & 4593 (30.13) & $1571(34.20)$ & & \\
\hline \multicolumn{5}{|l|}{ Age group, y } \\
\hline$\leq 31$ & 4089 (26.83) & 1467 (35.88) & 146.60 & $<0.01$ \\
\hline$>31$ and $\leq 37$ & $4117(27.01)$ & $1674(40.66)$ & & \\
\hline$>37$ and $\leq 43$ & 3291 (21.59) & $1236(37.56)$ & & \\
\hline$>43$ & $3746(24.57)$ & $1048(27.98)$ & & \\
\hline \multicolumn{5}{|l|}{ Region } \\
\hline Developed & $6000(39.36)$ & 2031 (33.85) & 13.13 & 0.01 \\
\hline Middle-developed & $4097(26.88)$ & 1499 (36.59) & & \\
\hline Less-developed & $5146(33.76)$ & $1895(36.82)$ & & \\
\hline \multicolumn{5}{|l|}{ Education level } \\
\hline $\begin{array}{l}\text { Associate's degree } \\
\text { or vocational } \\
\text { diploma }\end{array}$ & $894(5.86)$ & $230(25.73)$ & 41.21 & $<0.01$ \\
\hline Bachelor degree & $10293(67.53)$ & 3702 (35.97) & & \\
\hline $\begin{array}{l}\text { Master degree or } \\
\text { higher }\end{array}$ & $4056(26.61)$ & $1493(36.81)$ & & \\
\hline \multicolumn{5}{|l|}{ Marital status } \\
\hline $\begin{array}{l}\text { Married/widow/ } \\
\text { divorced }\end{array}$ & 12691 (83.26) & $4494(35.41)$ & 1.06 & 0.30 \\
\hline Unmarried & $2552(16.74)$ & 931 (36.48) & & \\
\hline \multicolumn{5}{|l|}{ Income status } \\
\hline High & $1672(10.97)$ & $398(23.80)$ & 312.27 & $<0.01$ \\
\hline Middle & $6746(44.26)$ & $2106(31.22)$ & & \\
\hline Low & $6825(44.77)$ & $2921(42.80)$ & & \\
\hline \multicolumn{5}{|l|}{ Work tenure, y } \\
\hline$\leq 3$ & $4921(32.28)$ & 1660 (33.73) & 48.49 & $<0.01$ \\
\hline$>3$ and $\leq 6$ & $3114(20.44)$ & $1173(37.67)$ & & \\
\hline$>6$ and $\leq 11$ & $3424(22.46)$ & $1351(39.46)$ & & \\
\hline$>11$ & $3784(24.82)$ & $1241(32.80)$ & & \\
\hline \multicolumn{5}{|l|}{ Contract status } \\
\hline Permanent & 9715 (63.73) & $3430(35.31)$ & 0.94 & 0.33 \\
\hline Temporary & $5528(36.27)$ & 1995 (36.09) & & \\
\hline \multicolumn{5}{|l|}{ Professional title } \\
\hline $\begin{array}{l}\text { Elementary or } \\
\text { below }\end{array}$ & 5349 (35.09) & $1933(36.14)$ & 103.13 & $<0.01$ \\
\hline Intermediate & $5861(38.45)$ & 2305 (39.33) & & \\
\hline Senior & $4033(26.46)$ & $1187(29.43)$ & & \\
\hline \multicolumn{5}{|l|}{ Ownership } \\
\hline Governmental & 14599 (95.78) & $5246(35.93)$ & 17.82 & $<0.01$ \\
\hline $\begin{array}{l}\text { Non-govern- } \\
\text { mental }\end{array}$ & $644(4.22)$ & $179(27.80)$ & & \\
\hline \multicolumn{5}{|l|}{ Level of hospital } \\
\hline Three-grade level & $10152(66.60)$ & 3661 (36.06) & 20.16 & $<0.01$ \\
\hline Two-grade level & 4841 (31.76) & $1708(35.28)$ & & \\
\hline Other & $250(1.64)$ & $56(22.40)$ & & \\
\hline
\end{tabular}


Table 1 (continued)

\begin{tabular}{|c|c|c|c|c|}
\hline Variables & $\mathrm{N}(\%)$ & $\begin{array}{l}\text { Depression } \\
\text { (CES-D Scores } \\
\geq 20 \text { ) }\end{array}$ & $x^{2}$ & $P$ value \\
\hline \multicolumn{5}{|l|}{ Shift work } \\
\hline Yes & $13288(87.17)$ & $5031(37.86)$ & 233.12 & $<0.01$ \\
\hline No & $1955(12.83)$ & $394(20.15)$ & & \\
\hline \multicolumn{5}{|c|}{ Workplace violence } \\
\hline Yes & $13699(89.87)$ & $5267(38.45)$ & 481.88 & $<0.01$ \\
\hline No & $1544(10.13)$ & $158(10.23)$ & & \\
\hline \multicolumn{5}{|c|}{ Self-perceived health status } \\
\hline Good & $4707(30.88)$ & $811(17.23)$ & 1781.32 & $<0.01$ \\
\hline Fair & $7729(50.71)$ & $2778(35.94)$ & & \\
\hline Poor & $2807(18.41)$ & $1836(65.41)$ & & \\
\hline \multicolumn{5}{|l|}{$\mathrm{BMI}\left(\mathrm{kg} / \mathrm{m}^{2}\right)$} \\
\hline$<25$ & $9588(62.90)$ & $3345(34.89)$ & 5.57 & 0.02 \\
\hline$\geq 25$ & $5655(37.10)$ & $2080(36.78)$ & & \\
\hline \multicolumn{5}{|c|}{ History of hypertension } \\
\hline Yes & $2317(15.20)$ & $1000(43.16)$ & 68.29 & $<0.01$ \\
\hline No & $12926(84.80)$ & $4425(34.23)$ & & \\
\hline \multicolumn{5}{|c|}{ History of diabetes } \\
\hline Yes & $598(3.92)$ & $257(42.98)$ & 14.81 & $<0.01$ \\
\hline No & 14645 (96.08) & $5168(35.29)$ & & \\
\hline \multicolumn{5}{|c|}{ History of coronary heart disease } \\
\hline Yes & $471(3.09)$ & $273(57.96)$ & 106.11 & $<0.01$ \\
\hline No & 14772 (96.91) & $5152(34.88)$ & & \\
\hline \multicolumn{5}{|c|}{ Smoking status } \\
\hline Nonsmokers & $12287(80.61)$ & $4265(34.71)$ & 21.34 & $<0.01$ \\
\hline Smokers & 2956 (19.39) & $1160(39.24)$ & & \\
\hline \multicolumn{5}{|c|}{ Alcohol drinking } \\
\hline Nondrinkers & $11451(75.12)$ & $4068(35.53)$ & 0.08 & 0.77 \\
\hline Drinkers & $3792(24.88)$ & 1357 (35.79) & & \\
\hline \multicolumn{5}{|c|}{ Physical inactivity } \\
\hline Yes & 4145 (27.19) & $1113(26.85)$ & 189.64 & $<0.01$ \\
\hline No & $11098(72.81)$ & $4312(38.85)$ & & \\
\hline \multicolumn{5}{|l|}{ Sleep quality } \\
\hline Good & $2295(15.06)$ & $250(10.89)$ & 1777.99 & $<0.01$ \\
\hline Fair & $7347(48.20)$ & $2058(28.01)$ & & \\
\hline Poor & $5601(36.74)$ & $3117(55.65)$ & & \\
\hline
\end{tabular}

Overall, $89.87 \%$ of respondents reported exposure to WPV in the previous 12 months (Table 1 ).

Overall, 5425 participants acquired CES-D scores equal to or greater than 20, which indicated that $35.59 \%$ of emergency physicians could suffer from depression. The factors associated with this psychological problems are presented in Table 2. Emergency physicians who were male $(\mathrm{OR}=0.91)$ and older $[>37$ and $\leq 43$ $(\mathrm{OR}=0.83)$ or $>43(\mathrm{OR}=0.71)]$, had high $(\mathrm{OR}=0.63)$ or middle $(\mathrm{OR}=0.70)$ level income, and participated in physical inactivity $(\mathrm{OR}=0.85)$ were not more likely to
Table 2 Logistic Analysis on the Influencing Factors of Emergency physicians' depression in China

\begin{tabular}{|c|c|c|c|c|c|}
\hline Variables & Coefficient & S.E. & $P$ & $O R$ & $95 \% \mathrm{Cl}$ \\
\hline \multicolumn{6}{|l|}{ Gender (Ref: Female) } \\
\hline Male & -0.10 & 0.05 & 0.04 & 0.91 & $0.83-0.10$ \\
\hline \multicolumn{6}{|l|}{ Age group, y (Ref: $\leq 31$ ) } \\
\hline$>31$ and $\leq 37$ & -0.09 & 0.07 & 0.16 & 0.91 & $0.80-1.04$ \\
\hline$>37$ and $\leq 43$ & -0.19 & 0.08 & 0.02 & 0.83 & $0.71-0.97$ \\
\hline$>43$ & -0.34 & 0.10 & $<0.01$ & 0.71 & $0.59-0.86$ \\
\hline \multicolumn{6}{|c|}{ Region (Ref: Less-developed) } \\
\hline Developed & -0.07 & 0.05 & 0.12 & 0.93 & $0.85-1.02$ \\
\hline Middle-developed & -0.02 & 0.05 & 0.73 & 0.98 & $0.89-1.08$ \\
\hline \multicolumn{6}{|c|}{ Education level (Ref: Associate's degree or vocational diploma) } \\
\hline Bachelor degree & 0.45 & 0.09 & $<0.01$ & 1.57 & $1.31-1.88$ \\
\hline Master degree or higher & 0.60 & 0.10 & $<0.01$ & 1.82 & $1.49-2.23$ \\
\hline \multicolumn{6}{|c|}{ Marital status (Ref: Married/widow/divorced) } \\
\hline Unmarried & 0.12 & 0.06 & 0.04 & 1.13 & $1.01-1.26$ \\
\hline \multicolumn{6}{|l|}{ Income level (Ref: Low) } \\
\hline High & -0.46 & 0.07 & $<0.01$ & 0.63 & $0.55-0.73$ \\
\hline Middle & -0.35 & 0.04 & $<0.01$ & 0.70 & $0.65-0.76$ \\
\hline \multicolumn{6}{|l|}{ Work tenure, y (Ref: $\leq 3$ ) } \\
\hline$>3$ and $\leq 6$ & 0.01 & 0.06 & 0.87 & 1.01 & $0.90-1.13$ \\
\hline$>6$ and $\leq 11$ & 0.14 & 0.06 & 0.02 & 1.15 & $1.02-1.30$ \\
\hline$>11$ & 0.17 & 0.07 & 0.01 & 1.19 & $1.04-1.36$ \\
\hline \multicolumn{6}{|c|}{ Contract status (Ref: Temporary) } \\
\hline Permanent & 0.07 & 0.04 & 0.11 & 1.07 & $0.98-1.17$ \\
\hline \multicolumn{6}{|c|}{ Professional title (Ref: Elementary or below) } \\
\hline Intermediate & 0.06 & 0.06 & 0.36 & 1.06 & $0.94-1.19$ \\
\hline Senior & 0.06 & 0.08 & 0.48 & 1.06 & $0.90-1.25$ \\
\hline \multicolumn{6}{|c|}{ Ownership (Ref: Non-governmental) } \\
\hline Governmental & 0.18 & 0.10 & 0.07 & 1.20 & $0.98-1.46$ \\
\hline \multicolumn{6}{|c|}{ Level of hospital (Ref: Other) } \\
\hline Three-grade level & 0.34 & 0.17 & 0.04 & 1.41 & $1.01-1.97$ \\
\hline Two-grade level & 0.33 & 0.17 & 0.05 & 1.40 & $1.00-1.95$ \\
\hline \multicolumn{6}{|l|}{ Shift work (Ref: No) } \\
\hline Yes & 0.32 & 0.07 & $<0.01$ & 1.38 & $1.20-1.58$ \\
\hline \multicolumn{6}{|c|}{ Workplace violence (Ref: No) } \\
\hline Yes & 1.26 & 0.09 & $<0.01$ & 3.51 & $2.94-4.20$ \\
\hline \multicolumn{6}{|c|}{ Self-perceived health status (Ref: Good) } \\
\hline Fair & 0.51 & 0.05 & $<0.01$ & 1.67 & $1.52-1.84$ \\
\hline Poor & 1.33 & 0.06 & $<0.01$ & 3.79 & $3.35-4.29$ \\
\hline \multicolumn{6}{|l|}{ BMI $\left(\mathrm{kg} / \mathrm{m}^{2}\right)($ Ref: <25) } \\
\hline$\geq 25$ & 0.01 & 0.04 & 0.85 & 1.01 & $0.93-1.09$ \\
\hline \multicolumn{6}{|c|}{ History of hypertension (Ref: No) } \\
\hline Yes & 0.12 & 0.06 & 0.03 & 1.13 & $1.01-1.26$ \\
\hline \multicolumn{6}{|c|}{ History of diabetes (Ref: No) } \\
\hline Yes & 0.12 & 0.10 & 0.23 & 1.13 & $0.93-1.38$ \\
\hline \multicolumn{6}{|c|}{ History of coronary heart disease (Ref: No) } \\
\hline Yes & 0.45 & 0.11 & $<0.01$ & 1.57 & $1.26-1.95$ \\
\hline \multicolumn{6}{|c|}{ Smoking status (Ref: Nonsmokers) } \\
\hline Smokers & 0.11 & 0.05 & 0.03 & 1.12 & $1.01-1.24$ \\
\hline
\end{tabular}


Table 2 (continued)

\begin{tabular}{lccccc}
\hline Variables & Coefficient & S.E. & $\boldsymbol{P}$ & OR & $\mathbf{9 5 \% ~ C l}$ \\
\hline $\begin{array}{l}\text { Alcohol drinking (Ref: Nondrinkers) } \\
\text { Drinkers }\end{array}$ & 0.04 & 0.05 & 0.37 & 1.05 & $0.95-1.15$ \\
$\begin{array}{l}\text { Physical inactivity (Ref: No) } \\
\text { Yes }\end{array}$ & -0.16 & 0.05 & $\mathbf{0 . 0 1}$ & 0.85 & $0.78-0.94$ \\
$\begin{array}{l}\text { Sleep quality (Ref: Good) } \\
\text { Fair }\end{array}$ & 0.80 & 0.08 & $<\mathbf{0 . 0 1}$ & 2.23 & $1.92-2.58$ \\
Poor & 1.60 & 0.08 & $<\mathbf{0 . 0 1}$ & 4.94 & $4.24-5.75$ \\
\hline
\end{tabular}

suffer depression. Meanwhile, those who were unmarried $(\mathrm{OR}=1.13)$ and smokers $(\mathrm{OR}=1.12)$ had higher education levels [Bachelor's degree $(\mathrm{OR}=1.57)$ or Master's degree or higher $(\mathrm{OR}=1.82)]$, long work tenure $[>6$ and $\leq 11(\mathrm{OR}=1.15)$ or $>11 ; 11(\mathrm{OR}=1.19)]$, poorer health status [fair $(\mathrm{OR}=1.67)$ or poor $(\mathrm{OR}=3.79)$ ] and sleep quality [fair $(\mathrm{OR}=2.23)$ or poor $(\mathrm{OR}=4.94)]$, had a history of hypertension $(\mathrm{OR}=1.13)$ and coronary heart disease $(\mathrm{OR}=1.57)$, and experienced violence $(\mathrm{OR}=1.91)$ and violence $(\mathrm{OR}=4.94)]$.

\section{Discussion}

To our knowledge, this is the largest cross-sectional survey of physicians' depression in the world, and we focused on emergency physicians, a community of physicians with high levels of work stress. We found that more than one-third of emergency physicians (35.59\%) suffered from depression. Compared to previous studies of surgeons $(20 \%)$ [22], primary health care workers (18\%) [23] and medical students (28.8\%) [24], emergency physicians showed higher levels of depression, which indicates that full attention should be given to this community. In addition, we identified a number of representative factors that clearly correlate with the increase in depression among emergency physicians, which could provide references for targeted measures.

\section{Age, gender, marital status and income level}

Our study found that emergency physicians who were older, male and had higher income levels were less likely to suffer from depression. These findings are consistent with previous studies. Liang et al. [37] reported that younger medical workers had higher self-rated depression scores than older medical workers. Erdur et al. [29] found that female and lower-paid emergency physicians were more likely to be depressed. Single doctors were more likely to report psychiatric symptoms [38], which is consistent with our findings. Although financial difficulties and additional responsibilities of family life may increase the likelihood of negative psychological effects on doctors, the family's social support mechanisms appear to play a role in preventing depression and anxiety [29]. Podder et al. [39] also mentioned that unmarried physicians are more stressed and more likely to have psychological problems. These findings suggest that more attention should be given to emergency physicians who are younger, female, unmarried and have low income.

\section{Education level and work tenure}

Well-educated workers tend to have higher career goals [40]. If career opportunities within the organization are limited, they are more likely to develop psychological problems [41]. Our study found that emergency physicians with higher education levels are more likely to develop depression, which could mean that these communities need adequate improvement opportunities. In addition, sense of achievement is an important factor that affects work enthusiasm [42]. Emergency physicians with longer working tenure may experience a decreased sense of professional accomplishment. Longer working tenure may lead to fatigue, tension and other psychological problems [43]. Erdur et al. [29] reported that emergency physicians with more working years were more likely to be depressed, and those who had been working in emergency departments for more than 10 years had the highest depression scores. Based on these results, one possible suggestion is that maintaining a sense of passion for work is a potential way to prevent depression among emergency physicians.

\section{Health status, sleep quality, physical inactivity and smoking}

Many studies have shown that a decline in health and sleep quality is an important factor in the development of depression [44-46]. Hypertension and coronary heart disease have also been reported to be associated with the occurrence of depression [47-49]. Our study also showed that emergency physicians with poor physical health and sleep quality were more likely to report depression. Emergency physicians who often participate in physical activity were less likely to be depressed, which is consistent with other studies on the relationship between exercise and depression [50,51]. In addition, smoking can be a reflection of depression. More specifically, it can be a mechanism of coping with depression [52]. A previous study reported that emergency department physicians had higher substance use rates than physicians in other specialties [53]. Erdur et al. also mentioned that emergency department physicians who smoked were markedly more likely to report psychological problems [29], which is in accordance with our results. Therefore, the managers of health institutions should focus on the health status of emergency physicians, while the 
physician community should develop healthy living habits. These measures could prevent psychological problems among these physicians.

\section{Shift work and workplace violence}

Because of scarce medical resources and a growing number of patients, emergency physicians are often required to work shifts [54]. Previous studies have shown that shift work is a risk factor for depression, anxiety and sleep disorders. Excessive shift work can lead to emergency physicians' depression. On the other hand, workplace violence in emergency departments has received increasing attention in recent years [55, 56]. A survey of the Occupational Health Safety Network (OHSN) in America during 2012-2015 showed that the incidence of emergency room violence was $19.3 \%$, with an average annual growth rate of 23\% [57], and previous studies have shown that only $30 \%$ of cases were documented $[58,59]$, while nearly $80 \%$ of cases were undocumented [60]. Wang et al. [61] found that workplace violence is a contributing factor to depression among physicians and that reducing violence would be beneficial to promoting the mental health status of medical staff, which is consistent with our findings. Therefore, targeted measures are needed to optimize the health service system, provide more flexible working regimes for emergency physicians, and mitigate doctorpatient relationships to reduce workplace violence.

China has the largest number of emergency physicians in the world, with nearly 60,000 , accounting for more than $2.1 \%$ of the total physicians, and it also receives the largest number of emergency patients each year, at more than 166.5 million [62]. This study found that $35.59 \%$ of them suffered from depression, which is higher than previous findings in the United Kingdom (18\%) [27], the United States (19.5\%) [28] and Turkey (29\%) [29], suggesting that there are different depression prevalences in different regions. Although emergency physicians in many countries also face intense work pressure and excessive numbers of patients, such as in China, the results of this study should still be interpreted with caution, and further exploration should be undertaken.

\section{Strengths, limitations and future suggestions}

Our study used a large-sample cross-sectional survey to explore the influencing factors of depression among emergency physicians. First, the large sample size significantly increased the statistical power. We surveyed nearly a quarter of the nation's emergency physicians; thus, the participants were representative. Second, this study included more than twenty potential contributors and produced many valuable findings, which reflects their working status and presents a broad view of the challenges faced by emergency physicians. Third, the survey was anonymous and self-administered, which likely made the respondents provide more valid responses and eliminated interviewer bias.

This study had several limitations. First, the study used a cross-sectional study design, which precluded the evaluation of the temporality of the observed relationships. Second, the data were collected from the participants' self-reports; thus, recall bias was unavoidable. Finally, the study was performed before the COVID-19 pandemic, which may have led to changes in the depression of emergency physicians after the pandemic.

Based on our findings, we suggest that, first, prospective studies are needed to investigate the association between the identified factors and depression. The identification of depression at a particular point in time or over a period of time is important, and further exploration is needed. Second, this study highlights the need for the investigation or implementation of interventions to improve emergency physicians' mental health or promote strategies to reduce work pressure in health care settings. Finally, investigating the potential impact of depression on emergency physicians' work performance, the quality of patient care delivery, and family life would provide important insights.

\section{Conclusion}

Our study found that nearly one third of emergency physicians in China suffered from depression, which is influenced by a variety of factors. Targeted measures should be taken to reduce the prevalence of depression to avoid a decline in health care quality and adversely impact the supply of emergency medical services. Emergency physicians who are female; younger; unmarried; smokers; have a low salary, higher education level, long working tenure, poor health status and sleep quality, history of hypertension and coronary heart disease; are frequent participants; and experience shift work and workplace violence should be given more attention.

\section{Abbreviations}

BMI: Body Mass Index; CES-D: Center for Epidemiological Studies-Depression Scale.

\section{Acknowledgements}

We would like to thank the study participants and all staff members involved in this study for their efforts in the data collection.

\section{Authors' contributions}

Y.M.C., X.S. and C.Z.L. conceived and designed the study. J.F. and Z.H.L. participated in the acquisition of data. Y.M.C. and X.Y.S. analyzed the data. W.Z. and X.Y.S. gave advice on methodology. Y.M.C. and X.S. drafted the manuscript. Y.M.C. and C.Z.L. revised the manuscript. All authors read and approved the final manuscript. C.Z.L. is the guarantor of this work and had full access to all the data in the study and takes responsibility for its integrity and the accuracy of the data analysis. 


\section{Funding}

This study was supported by the Hainan Provincial Natural Science Foundation of China (821QN414) and Hainan Province Clinical Medical Center.

\section{Availability of data and materials}

Data may be made available by contacting the corresponding author.

\section{Declarations}

\section{Consent to publication}

Not applicable

\section{Ethics approval and consent to participate}

All individuals provided written informed consent. This study was performed in line with the principles of the Declaration of Helsinki. The protocol strictly abided by the Chinese Statistical Law to ensure that participants' personal information was kept confidential. The protocol was approved by Institutional Ethics Board of the Second Affiliated Hospital of Hainan Medical University, Haikou, China, in accordance with the Chinese Statistical Law.

\section{Competing interests}

We declare that we have no conflict of interests.

\section{Author details}

${ }^{1}$ Central People's Hospital of Zhanjiang, Zhanjiang, Guangdong, China.

${ }^{2}$ Department of Social Medicine and Health Management, School of Public Health, Tongji Medical College, Huazhong University of Science and Technology, Wuhan, Hubei, China. ${ }^{3}$ School of Public Health, Jilin University, Changchun, Jilin, China. ${ }^{4}$ Department of Emergency, Hainan Clinical Research Center for Acute and Critical Diseases, The Second Affiliated Hospital of Hainan Medical University, No. 368 Yehai Avenue, Longhua Zone, Haikou 571199, Hainan, China. ${ }^{5}$ Emergency Medicine Center, Sichuan Provincial People's Hospital, University of Electronic Science and Technology of China, No. 32 Yi Huan Lu Xi Er Duan, Chengdu 610072, Sichuan Province, China. ${ }^{6}$ Research Unit of Island Emergency Medicine, Chinese Academy of Medical Sciences (No. 2019RU013), Hainan Medical University, Haikou, Hainan, China.

Received: 15 July 2021 Accepted: 3 January 2022

Published online: 28 January 2022

\section{References}

1. Cuijpers P, Vogelzangs N, Twisk J, Kleiboer A, Li J, Penninx BW. Comprehensive meta-analysis of excess mortality in depression in the general community versus patients with specific illnesses. Am J Psychiatry. 2014;171(4):453-62.

2. Demyttenaere K, Bruffaerts R, Posada-Villa J, Gasquet I, Kovess V, Lepine $J$, et al. Prevalence, severity, and unmet need for treatment of mental disorders in the World Health Organization World Mental Health Surveys. JAMA. 2004:291(21):2581-90.

3. Steel Z, Marnane C, Iranpour C, Chey T, Jackson JW, Patel V, et al. The global prevalence of common mental disorders: a systematic review and meta-analysis 1980-2013. Int J Epidemiol. 2014;43(2):476-93.

4. Whiteford HA, Degenhardt L, Rehm J, Baxter AJ, Ferrari AJ, Erskine HE, et al. Global burden of disease attributable to mental and substance use disorders: findings from the Global Burden of Disease Study 2010. Lancet. 2013;382(9904):1575-86.

5. Smith K. Mental health: a world of depression. Nature. 2014:515(7526):180-1.

6. Goldberg RJ, Steury S. Depression in the workplace: costs and barriers to treatment. Psychiatr Serv. 2001:52(12):1639-43.

7. Mata DA, Ramos MA, Bansal N, Khan R, Guille C, Di Angelantonio E, et al. Prevalence of depression and depressive symptoms among resident physicians: a systematic review and meta-analysis. JAMA 2015:314(22):2373-83.

8. Clarke DM, Currie KC. Depression, anxiety and their relationship with chronic diseases: a review of the epidemiology, risk and treatment evidence. Med J Aust. 2009;(S7):190, S54-60
9. Glassman AH, Shapiro PA. Depression and the course of coronary artery disease. Am J Psychiatry. 1998;155(1):4-11.

10. Rubin R. Recent Suicides Highlight Need to Address Depression in Medical Students and Residents. JAMA. 2014;312(17):1725-7.

11. Wallace JE, Lemaire JB, Ghali WA. Physician wellness: a missing quality indicator. The Lancet, 2009. 374(9702):1714-21.

12. West CP, Huschka MM, Novotny PJ, Sloan JA, Kolars JC, Habermann TM, et al. Association of perceived medical errors with resident distress and empathy: a prospective longitudinal study. JAMA. 2006;296(9):1071-8.

13. Fahrenkopf AM, Sectish TC, Barger LK, Sharek PJ, Lewin D, Chiang VW, et al. Rates of medication errors among depressed and burnt out residents: prospective cohort study. BMJ. 2008;336(7642):488-91.

14. Gong Y, Han T, Chen W, Dib HH, Yang G, Zhuang R, et al. Prevalence of anxiety and depressive symptoms and related risk factors among physicians in China: a cross-sectional study. Plos One. 2014;9(7):e103242.

15. Arora M, Asha S, Chinnappa J, Diwan AD. Review article: burnout in emergency medicine physicians. Emerg Med Australas. 2013;25(6):491-5.

16. Bragard I, Dupuis G, Fleet R. Quality of work life, burnout, and stress in emergency department physicians: a qualitative review. Eur J Emerg Med. 2015:22(4):227-34

17. Song X, Fu W, Liu X, Luo Z, Wang R, Zhou N, et al. Mental health status of medical staff in emergency departments during the Coronavirus disease 2019 epidemic in China. Brain Behav Immun. 2020;88:60-5.

18. Schneider SE, Phillips WM. Depression and anxiety in medical, surgical, and pediatric interns. Psychol Rep. 1993:72(3 Pt 2):1145-6.

19. Kessler RC, Berglund P, Demler O, Jin R, Merikangas KR, Walters EE. Lifetime prevalence and age-of-onset distributions of DSM-IV disorders in the National Comorbidity Survey Replication. Arch Gen Psychiatry. 2005:62(6):593-602

20. Dyrbye LN, Thomas MR, Shanafelt TD. Systematic review of depression, anxiety, and other indicators of psychological distress among U.S. and Canadian medical students. Acad Med. 2006;81(4):354-73.

21. Sen S, Kranzler HR, Krystal JH, Speller H, Chan G, Gelernter J, et al. A prospective cohort study investigating factors associated with depression during medical internship. Arch Gen Psychiatry. 2010;67(6):557-65.

22. Lin DT, Liebert CA, Esquivel MM, Tran J, Lau JN, Greco RS, et al. Prevalence and predictors of depression among general surgery residents. Am J Surg. 2017:213(2):313-7.

23. Da Silva ATC, Lopes CDS, Susser E, Menezes PR. Work-Related Depression in Primary Care Teams in Brazil. Am J Public Health. 2016:106(11):1990-7.

24. Schipper S. High prevalence of depression in medical residents: the sad reality of medical training. Evidence Based Med. 2016;21(3):118.

25. Hsu K, Marshall V. Prevalence of depression and distress in a large sample of Canadian residents, interns, and fellows. Am J Psychiatry. 1987:144(12):1561-6

26. Hsieh YH, Hsu CY, Liu CY, Huang TL. The levels of stress and depression among interns and clerks in three medical centers in Taiwan--a crosssectional study. Chang Gung Med J. 2011;34(3):278-85.

27. Burbeck R, Coomber S, Robinson SM, Todd C. Occupational stress in consultants in accident and emergency medicine: a national survey of levels of stress at work. Emerg Med J. 2002;19(3):234-8.

28. Gallery ME, Whitley TW, Klonis LK, Anzinger RK, Revicki DA. A study of occupational stress and depression among emergency physicians. Ann Emerg Med. 1992;21(1):58-64.

29. Erdur B, Ergin A, Turkcuer I, Parlak I, Ergin N, Boz B. A study of depression and anxiety among doctors working in emergency units in Denizli, Turkey. Emerg Med J. 2006;23(10):759-63.

30. von Elm E, Altman DG, Egger M, Pocock SJ, Gøtzsche PC, Vandenbroucke $J P$. The Strengthening the Reporting of Observational Studies in Epidemiology (STROBE) Statement: Guidelines for reporting observational studies. Int J Surg. 2014;12(12):1495-9.

31. Wang PX, Wang MZ, Hu GX, Wang ZM. Study on the relationship between workplace violence and work ability among health care professionals in Shangqiu City. Wei Sheng Yan Jiu. 2006:35(4):472-4.

32. Cosco TD, Lachance CC, Blodgett JM, Stubbs B, Co M, Veronese N, et al. Latent structure of the Centre for Epidemiologic Studies Depression Scale (CES-D) in older adult populations: a systematic review. Aging Ment Health. 2020;24(5):700-4.

33. Dozeman E, van Schaik DJ, van Marwijk HW, Stek ML, van der Horst HE, Beekman AT. The center for epidemiological studies depression scale (CES-D) is an adequate screening instrument for depressive and anxiety 
disorders in a very old population living in residential homes. Int J Geriatr Psychiatry. 2011;26(3):239-46.

34. Cheng ST, Chan AC. The Center for Epidemiologic Studies Depression Scale in older Chinese: thresholds for long and short forms. Int I Geriatr Psychiatry. 2005;20(5):465-70.

35. Vilagut G, Forero CG, Barbaglia G, Alonso J. Screening for Depression in the General Population with the Center for Epidemiologic Studies Depression (CES-D): A Systematic Review with Meta-Analysis. PLOS ONE. 2016, 11(5):e155431.

36. Jiang L, Wang Y, Zhang Y, Li R, Wu H, Li C, et al. The Reliability and Validity of the Center for Epidemiologic Studies Depression Scale (CES-D) for Chinese University Students. Front Psychiat. 2019;10:315.

37. Liang Y, Chen M, Zheng X, Liu J. Screening for Chinese medical staff mental health by SDS and SAS during the outbreak of COVID-19. J Psychosom Res. 2020;133:110102.

38. Chan AO, Huak CY. Psychological impact of the 2003 severe acute respiratory syndrome outbreak on health care workers in a medium size regional general hospital in Singapore. Occup Med (Lond). 2004;54(3):190-6.

39. Podder I, Agarwal K, Datta S. Comparative analysis of perceived stress in dermatologists and other physicians during national lock-down and COVID-19 pandemic with exploration of possible risk factors: A web-based cross-sectional study from Eastern India. Dermatol Ther. 2020;33(4):e13788.

40. Greco LM, Kraimer ML. Goal-setting in the career management process: An identity theory perspective. J appl psychol. 2020;105(1):40-57.

41. Arnetz BB. Psychosocial challenges facing physicians of today. Soc Sci Med. 2001;52(2):203-13.

42. Colindres CV, Bryce E, Coral-Rosero P, Ramos-Soto RM, Bonilla F, Yassi A. Effect of effort-reward imbalance and burnout on infection control among Ecuadorian nurses. Int Nurs Rev. 2018:65(2):190-9.

43. Herda DN, Lavelle JJ. The Auditor-Audit Firm Relationship and Its Effect on Burnout and Turnover Intention. Account Horiz. 2012;26(4):707-23.

44. Chen F, Lin X, Pan Y, Zeng X, Zhang S, Hu H, et al. Insomnia partially mediates the relationship between pathological personality traits and depression: a case-control study. Peerj. 2021;9:e11061.

45. Wang J, Wu X, Lai W, Long E, Zhang X, Li W, et al. Prevalence of depression and depressive symptoms among outpatients: a systematic review and meta-analysis. Bmj Open. 2017;7(8):e17173.

46. Tsuno N, Besset A, Ritchie K. Sleep and depression. J Clin Psychiatry. 2005;66(10):1254-69.

47. Raič M. Depression and Heart Diseases: Leading Health Problems. Psychiatr Danub. 2017;4(Suppl 4):770-7.

48. Seligman F, Nemeroff CB. The interface of depression and cardiovascular disease: therapeutic implications. Ann N Y Acad Sci. 2015;1345:25-35.

49. Péter L, Döme P, Rihmer Z, Kovács G, Faludi G. Cardiovascular disorders and depression: a review of epidemiological and possible etiological data. Neuropsychopharmacol Hung. 2008;10(2):81-90.

50. Ströhle A. Physical activity, exercise, depression and anxiety disorders. J Neural Transm (Vienna). 2009;1 16(6):777-84.

51. Carek PJ, Laibstain SE, Carek SM. Exercise for the treatment of depression and anxiety. Int J Psychiatry Med. 2011;41(1):15-28.

52. Fluharty M, Taylor AE, Grabski M, Munafò MR. The Association of Cigarette Smoking With Depression and Anxiety: A Systematic Review. Nicotine Tob Res. 2017;19(1):3-13.

53. Hughes PH, Baldwin DJ, Sheehan DV, Conard S, Storr CL. Resident physician substance use, by specialty. Am J Psychiatry. 1992;149(10):1348-54.

54. Philippon AL. Work shift duration for emergency physicians - the shorter, the better: the French Experience. Eur J Emerg Med. 2019;26(6):396-7.

55. Ramacciati N, Ceccagnoli A, Addey B, Lumini E, Rasero L. Violence towards emergency nurses: A narrative review of theories and frameworks. Int Emerg Nurs. 2018;39:2-12.

56. Zafar W, Siddiqui E, Ejaz K, Shehzad MU, Khan UR, Jamali S, et al. Health care personnel and workplace violence in the emergency departments of a volatile metropolis: results from Karachi, Pakistan. J Emerg Med. 2013:45(5):761-72.

57. Groenewold MR, Sarmiento R, Vanoli K, Raudabaugh W, Nowlin S, Gomaa A. Workplace violence injury in 106 US hospitals participating in the Occupational Health Safety Network (OHSN), 2012-2015. Am J Ind Med. 2018;61(2):157-66.
58. Erickson L, Williams-Evans SA. Attitudes of emergency nurses regarding patient assaults. J Emerg Nurs. 2000;26(3):210-5.

59. Partridge B, Affleck J. Verbal abuse and physical assault in the emergency department: Rates of violence, perceptions of safety, and attitudes towards security. Australas Emerg Nurs J. 2017;20(3):139-45.

60. Pinar R, Ucmak F. Verbal and physical violence in emergency departments: a survey of nurses in Istanbul, Turkey. J Clin Nurs. 2011;20(3-4):510-7.

61. Wang $H$, Zhang $Y$, Sun $L$. The effect of workplace violence on depression among medical staff in China: the mediating role of interpersonal distrust. Int Arch Occup Environ Health. 2021;94(3):557-64.

62. Pan C, Pang J, Cheng K, Xu F, Chen Y. Trends and challenges of emergency and acute care in Chinese mainland: 2005-2017. World J Emerg Med. 2021;12(1):5-11.

\section{Publisher's Note}

Springer Nature remains neutral with regard to jurisdictional claims in published maps and institutional affiliations.
Ready to submit your research? Choose BMC and benefit from:

- fast, convenient online submission

- thorough peer review by experienced researchers in your field

- rapid publication on acceptance

- support for research data, including large and complex data types

- gold Open Access which fosters wider collaboration and increased citations

- maximum visibility for your research: over $100 \mathrm{M}$ website views per year

At BMC, research is always in progress.

Learn more biomedcentral.com/submissions 